\title{
The growing problem of diabetes
}

\author{
Fiona Godlee editor in chief
}

The BMJ

Type 2 diabetes affects nearly $10 \%$ of the world's adults, and rates are rising rapidly, especially in low and middle income countries. ${ }^{1}$ In the UK it affects about four million adults $(6 \%$ of the population), and if nothing changes this will grow to about five million by $2025 .^{2}$ And new figures released this week by Diabetes UK show that in England and Wales nearly 7000 people under age 25 now have type 2 diabetes (doi:10.1136/ bmj.k4929).

With such numbers, diabetes in one form or another now makes up a substantial part of any doctor's day (doi:10.1136/bmj. k4723). So what can you do for your diabetic patients? Firstly, don't call them that, says Judith Hendley (doi:10.1136/bmj. $\mathrm{k} 3119$ ). She wants to be identified as a person first and not as a diabetic patient, a label that reduces her "to someone with diabetes and nothing else."

Secondly, consider your use of language generally. Hendley suggests avoiding questions such as "Are you well controlled?" She says, "This feels like a question about my behaviour and how 'good' I have been." Better to ask open questions that don't judge or make assumptions, for example: are you having any difficulties with your blood sugar at the moment, and what is most important to you right now? Such reframing may sound trivial, but, says Hendley, it "could make a big difference to how the people in front of you see themselves and their condition-and how they see you."
As for the factors behind the global diabetes epidemic, there's always more to learn. Analysis of data from two large cohorts of nurses confirms the key role of unhealthy lifestyles (doi:10. 1136/bmj.k4641). A systematic review looks specifically at the effect of fructose on glycaemic control and concludes that this depends on the source of fructose and how much extra energy it provides (doi:10.1136/bmj.k4644). Sweetened drinks and some other foods that add excess "nutrient poor" energy were most likely to adversely affect glycaemic control.

Weight loss is essential for management of diabetes and can lead to remission, but once achieved it can be hard to maintain. In what may be a ground breaking randomised trial, Cara Ebbeling and colleagues found that energy expenditure was higher when people ate a low carbohydrate diet during weight loss maintenance (doi:10.1136/bmj.k4583). People randomised to a high carbohydrate diet had higher concentrations of the hormone ghrelin, which is thought to reduce energy expenditure. Ultimately the burden of diabetes is unsustainable. While patients and health professionals manage as best they can, the real and urgent solutions rest with our governments.

World Health Organization. Global report on diabetes. www.who.int/diabetes/global-report/ en

Diabetes UK. The cost of diabetes. https://www.diabetes.org.uk/resources-s3/2017-11/ diabetes\%20uk\%20cost\%20of\%20diabetes\%20report.pdf.

Published by the BMJ Publishing Group Limited. For permission to use (where not already granted under a licence) please go to http://group.bmj.com/group/rights-licensing/ permissions 